\title{
Injury Epidemiology of 626 Athletes in Surfing, Wind Surfing and Kite Surfing
}

\author{
Dominik Szymski (iD) \\ Leonard Achenbach ${ }^{2,3}$ \\ Martin Siebentritt ${ }^{4}$ \\ Karola Simoni ${ }^{5}$ \\ Norbert Kuner ${ }^{5}$ \\ Christian Pfeifer ${ }^{1}$ \\ Werner Krutsch ${ }^{1,6}$ \\ Volker Alt ${ }^{\prime}$ \\ Rainer Meffert ${ }^{2}$ \\ Kai Fehske (iD ${ }^{2}$ \\ 'Department of Trauma Surgery, \\ University Medical Centre Regensburg, \\ Regensburg, Germany; ${ }^{2}$ Department of \\ Trauma-, Hand-, Plastic- and \\ Reconstructive Surgery, University \\ Wuerzburg, Wuerzburg, Germany; \\ ${ }^{3}$ Department of Orthopaedics, Koenig- \\ Ludwig-Haus, University Wuerzburg, \\ Wuerzburg, Germany; ${ }^{4}$ Department for \\ Anesthesiology and Operative Intensive \\ Care, Bayreuth, Germany; ${ }^{5}$ General \\ Medicine and Dermatology, Medical \\ Center for General Medicine, \\ Dermatology, Paediatrics and Internal \\ Medicine, Costa Calma Fuerteventura, \\ Costa Calma, Spain; ${ }^{6}$ Sports-Orthopedics, \\ SportDocs Franken, Nuremberg, Germany
}

Correspondence: Kai Fehske Department of Trauma-, Hand-, Plasticand Reconstructive Surgery, University Wuerzburg, Wuerzburg, Germany

Tel +49 931 201 3700I

Fax +49 931 201 37009

Email kai.fehske@ukw.de
Introduction/Background: Surfing, wind surfing and kite surfing enjoy a growing popularity with a large number of athletes worldwide. The aim of this study was to identify and compare the injury profiles and compare the injury profiles of these three extreme water sports.

Materials and Methods: These data for this retrospective cohort study were collected through an online standardised questionnaire during the 2017-18 season. The questionnaire included questions about anthropometry, skill level, injury diagnosis, injury mechanism, environmental conditions and training regimes.

Results: The 626 athletes included reported 2584 injuries. On average, each athlete sustained 4.12 injuries during the season. The most frequent injury location was in the lower extremity, in particular the foot, with 49 (16.4\%) injuries in surfing, 344 (18.3\%) in wind surfing and $79(19.7 \%)$ in kite surfing. Surfing demonstrated a particularly high rate of head injuries $(n=37 ; 12.4 \%)$. Other frequent injury types were skin lesions (up to $42.1 \%$ ) and contusions (up to $40.5 \%$ ). The most common injury across all surfing sports was skin lesions of the foot (wind surfing: $11.7 \%$; kite surfing: 13.2\%; surfing: $12.7 \%$ ). In surfing, skin lesions of the head were frequently observed $(n=24 ; 8.0 \%)$. In surfing, a 'too large wave' $(n=18$; $24.7 \%)$ was main cause of the injury, while in wind surfing $(\mathrm{n}=189 ; 34.5 \%)$ and kite surfing $(\mathrm{n}=65 ; 36.7 \%)$ 'own incompetence' led to the most injuries.

Conclusion: This unique study compares injury epidemiology and mechanism in the three most popular surfing sports: wind surfing, kite surfing and surfing. Overall, injuries were sustained mainly in the lower extremity, while surfing also demonstrated a high rate of head injuries.

Keywords: water sports, injury, training, ankle, foot, epidemiology

\section{Introduction}

Water sports are rapidly growing in popularity worldwide. Surfing sports in particular, such as wind surfing, kite boarding and surfing, annually gain active athletes. An estimate by the International Surfing Association counts more than 23 million surfers and around 35 million windsurfers. The population of active athletes in kite surfing is estimated to be lower, but also rapidly growing with up to 3.5 million athletes. Due to a high number of individual recreational athletes, no detailed data about participants is available and estimates are based on sales numbers and travel reservations. ${ }^{5}$ With the growing popularity of these extreme sports comes an ever increasing number of injuries. ${ }^{14}$

Despite growing interest and athlete numbers, epidemiological injury statistics in this field are few and far between. Current literature focuses on competitive 
athletes or sub-group analysis of trauma centre registries and lacks detailed information on injury circumstances. ${ }^{3,10,11,16-18,23}$ In surfing, the unique combination of paddling, wave riding, and waiting exposes the body to several different forces. During a fall, for example, control of the board and the body is limited. ${ }^{8}$ Kite surfers are exposed to particularly strong winds on open seas, where speeds of up to $33 \mathrm{~km} / \mathrm{h}$ are common., ${ }^{9,10}$ As well as high speeds of up to $65 \mathrm{~km} / \mathrm{h}$ (35 knots), jumps of $15 \mathrm{~m}$ height and $30 \mathrm{~m}$ length, and various mid-air manoeuvres are responsible for injuries in kite- and wing surfing. Additionally, holding the sail in wind surfing requires great strength to transfer the energy from the sail to the board. $^{1,28}$

Despite differences in the movement process, the sports are similar in terms of target group, place of practice and growing worldwide popularity. A comparative study of injury epidemiology across these three water sports is still lacking. For this reason, this aim of this study was to explore and compare the epidemiology of injuries between surfing, kite surfing, and windsurfing. An analysis of the training habits of all athletes was included in order to draw further conclusions about similarities and differences in these sports. The aim of this study was to identify differences in injury mechanism and principal prevention aspects between surfing, wind surfing and kite surfing.

\section{Materials and Methods}

\section{Study Population}

This retrospective cohort study compared data from surfers, windsurfers and kite surfers. Anthropometric data, injuries, surfing habits, environmental issues and training patterns were recorded retrospectively between July 2017 to September 2018 using an standardized online questionnaire. For this purpose, information was distributed to surf stores and spots worldwide via magazines, websites, flyers and notices.

All participants were informed about the aim, content and objectives of the study and written consent was obtained. Included were all athletes who participated in one of the indicated surfing sports and obtained an injury in the study period between July 2017 and September 2018 and filled out the questionnaire. An injury was defined as time-loss injury of at least one training session. Missing consent, a missing injury report or age under 18 were exclusion criteria. While opening the online-questionnaire was recorded, incomplete data records were excluded from the study to ensure valid and complete data.

The study protocol was approved by the Ethical Review Board of the Medical University of Wuerzburg.

\section{Data Collection}

Data collection was conducted using a standardized demographic baseline questionnaire, which included information about age, height, weight and experience in the sport. Athletes were also asked to rank their skill on a scale between 1 and 6 , with 6 being the maximum. ${ }^{7}$ Data about environmental conditions while the injury was sustained, such as wind force and height of waves, and material used (boards, sails/kite) was recorded as well. Athletes were asked to fill out information about injury mechanism, diagnosis and treatment. The localization, severity and type of injury were registered. Injury severity was classified according to Krutsch et al into severe (ruptures, fractures, dislocations and concussions) and non-severe (skin lesions, sprains strains, contusions and inflammations) injuries. ${ }^{19}$ The questionnaire further assessed the annual surfing time, additional sporting activities, and a self-assessment of the athlete's physical condition and time to return to sports. The main aim of the study was the analysis of injuries in surfing, wind surfing and kite surfing with regard to epidemiology, prevalence and mechanism of injuries. The athletes were classified according to the sport in which the injury occurred.

\section{Statistical Analysis}

Continuous data is expressed as mean \pm standard deviation (SD) and categorical data as frequency counts (percentages). Odds ratios and rate ratios accompanied by the corresponding 95\% confidence interval (CI) are reported as effect estimates. The Chi-square test was used to investigate the dependence on qualitative characteristics, while association strength was calculated using the Pearson-Test and Fisher-Test. The significance level was set to $\mathrm{p}<0.05$. All analyses were performed with IBM SPSS Statistics, version 26.0 .

\section{Results}

The questionnaire was accessed 1507 times. Complete data were collected from 626 participants. Of all athletes, $881(58.5 \%)$ of the participants were excluded due to incomplete data. Overall, most athletes were active wind surfers $(n=435 ; 69.5 \%)$, followed by kite surfers $(n=134$; $21.4 \%)$ and surfers $(n=57 ; 9.1 \%)$. Wind surfing athletes 
Table I Anthropometric Data of the Study Population

\begin{tabular}{|l|l|l|l|}
\hline & Surfing (S) & Wind Surfing (WS) & Kite Surfing (KS) \\
\hline Participants & 57 & 435 & 134 \\
Male:Female ratio & $1: 0.30$ & $1: 0.14$ & $1: 0.28$ \\
Age & $28.0 \pm 9.8$ & $34.6 \pm 12.0 * *$ & $31.2 \pm 9.3 *$ \\
Weight in kg & $73.2 \pm 11.3$ & $77.5 \pm 12.2 *$ & $75.8 \pm 11.2$ \\
Height in cm & $178 \pm 7$ & $181 \pm 8 *$ & $179 \pm 8$ \\
BMl in kg/m & $22.9 \pm 2.9$ & $23.7 \pm 3.0$ & $23.5 \pm 2.6$ \\
Experience in years & $10.0 \pm 8.8 *$ & $13.6 \pm 9.8 * *$ & $6.2 \pm 6.9$ \\
Experience in levels (I-6) & $4.2 \pm 1.3$ & $4.3 \pm 1.2$ & $3.8 \pm 1.5$ \\
\hline
\end{tabular}

Notes: $*_{p}<0.05 ; * * p<0.001$.

were more experienced compared to kite surfers $(\mathrm{p}<$ 0.001) (Table 1).

A total of 2584 injuries were sustained - on average one athlete indicated 4.12 injuries in one season. The highest prevalence was registered in surfing with 5.25 injuries followed by wind surfing with 4.33 and 3.0 in kite surfing. The majority of the injuries $(n=1883$; $72.8 \%$ ) occurred during windsurfing, while 402 (15.6\%) occurred during kite surfing and 299 (11.6\%) during surfing. In all three types of surfing, injuries primarily involved the foot $(16.4-19.7 \%)$. Head $(n=37 ; 12.4 \%)$ injuries were sustained most frequently in surfing (Figure 1). When considering the type of injury, skin lesions and contusions were the most common injuries observed in all three sports (Figure 2). Skin lesions of the foot were the major injury across all forms of surfing. Skin lesions of the head $(\mathrm{n}=24 ; 8.0 \%)$ were also common in surfing (Table 2).

With 292 injuries (53.3\%), the majority of lesions in wind surfing occurred under wind conditions between 5 and 9 on the Beaufort scale (Bft). In kite surfing injuries appeared especially between 3 and $5 \mathrm{Bft}(\mathrm{n}=108,61.0 \%)$. In surfing with $74.0 \%$, the majority of injuries $(n=54)$ were registered in surges between 1 and 3 meters. For the injury mechanism, $24.7 \%$ of surfers stated a 'too strong surf', while in wind surfing and kite surfing mainly 'own incompetence' $(34.5 \%$ vs $36.7 \%)$ and skidding falls (28.8\% vs $25.4 \%$ ) were registered (Table 3).

In surfing (63.9\%) and kite surfing $(45.3 \%)$, most athletes spent more than 30 days training in their respective sport per year, while in windsurfing the training workload of most athletes was between 14 and 30 days $(n=192$; $42.6 \%$ ). In surfing, the athletes mainly indicated strength training ( $\mathrm{n}=31 ; 50.8 \%)$, snowboarding $(\mathrm{n}=31 ; 50.8 \%)$ and skateboarding $(\mathrm{n}=26 ; 42.6 \%)$ as compensatory sports.
Strength training $(n=178 ; 39.5 \%)$, skiing $(n=159 ; 35.3 \%)$ and mountain biking $(\mathrm{n}=138 ; 30.6 \%)$ were particularly popular among wind surfers. A similar picture emerged among kite surfers, for whom snowboarding $(n=70$; $51.1 \%)$ followed by strength training $(n=63 ; 46.0 \%)$ and mountain biking $(n=45 ; 32.8 \%)$ were among the most popular sports (Table 4).

\section{Discussion}

The main finding of this study was the identification of the lower extremity as most frequent injury location in all three types of surfing sport. The proportion of injuries ranged between $35.5 \%$ in surfing and $51.5 \%$ in kite surfing. Across all three disciplines, the foot was the most common injury location. In particular, skin lesions of the foot proved to be the most frequent injury.

A high proportion of surfing injuries were located on the head, the most common being skin lesions. This extends findings from Sunshine et al who identified head and neck injuries in surfing as one of the most common locations. Minor superficial traumas treated with sutures were primarily reported. The lacerations often occurred as a result of a collision with the board or the sea ground, and are one reason for the increasing use of head protection in surfing. ${ }^{3,16,32}$

Most of the injuries sustained in surfing are to the lower extremities. Turning and aerial manoeuvres performed by more advanced surfers are responsible for higher impacts and loads on joints and soft tissue of the lower extremity. ${ }^{23,27,32}$ Previous literature describes a low incidence between 6.6 and 13 injuries per $1000 \mathrm{~h}$ of surfing. ${ }^{14,23,32}$ Dyson et al studied wind surfing and also describe a high frequency of injuries in the lower extremity. However, they also determined a high rate of lower back injuries, which we could not verify. ${ }^{7}$ Other 


\section{Percentage of injury location}

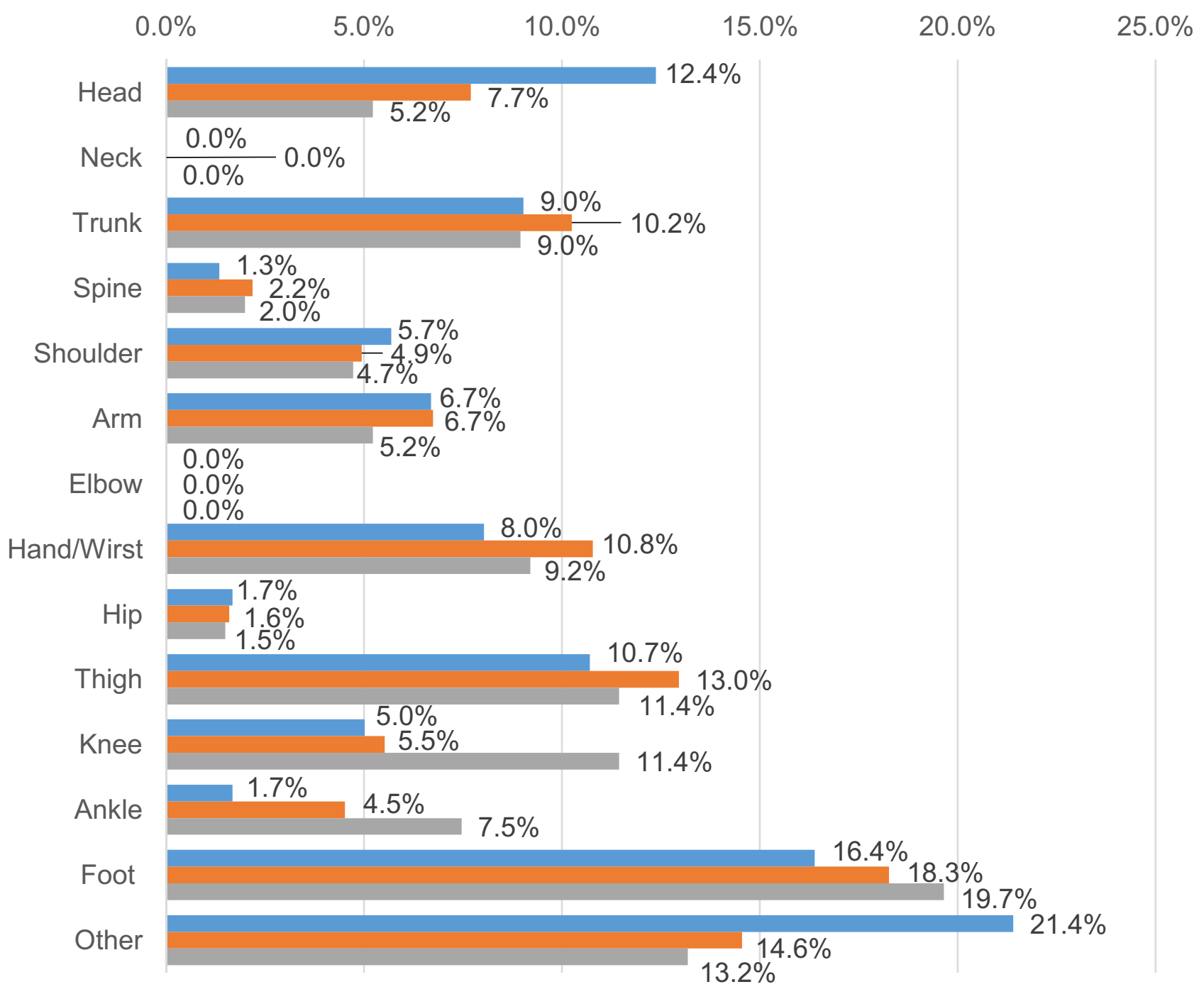

Surfing $\quad$ Wind Surfing $\quad$ Kite Surfing

Figure I Distribution of injury location among surfing sports.

publications on wind surfing injuries also identified the foot and ankle as main spot for injuries. ${ }^{1,22}$ High forces exerted on joints of the lower extremity during surfing sports are the most plausible reason for the injury rates. While athletes need a fixation of the foot and ankle on the board, this fixation mechanism is a potential risk factor for injuries. A self-release mechanism may be a method of severe injury reduction in the lower extremity and in particular the ankle. Up to 5.2 injuries in 1000 hours of wind surfing exposure were registered in previous investigations with mainly muscle strains in the lower body. ${ }^{1,7}$ In current literature, kite- and wind surfing injuries of the lower extremity were mainly found to affect the ankle and foot. ${ }^{2,6,24}$ In non-competitive athletes, 5.9 to 7.0 injuries were in 1000 hours of kite surfing documented, most of which concerned the musculoskeletal system of the lower extremity. In professional kite surfers, the rate of injuries is even higher (up to 16.6). ${ }^{1,2,15,24,27}$

The distribution of injury types across the sports painted a fairly homogenous picture. The most common injuries were minor, such as skin lesions and contusions. The high proportion of skin lesions was already 


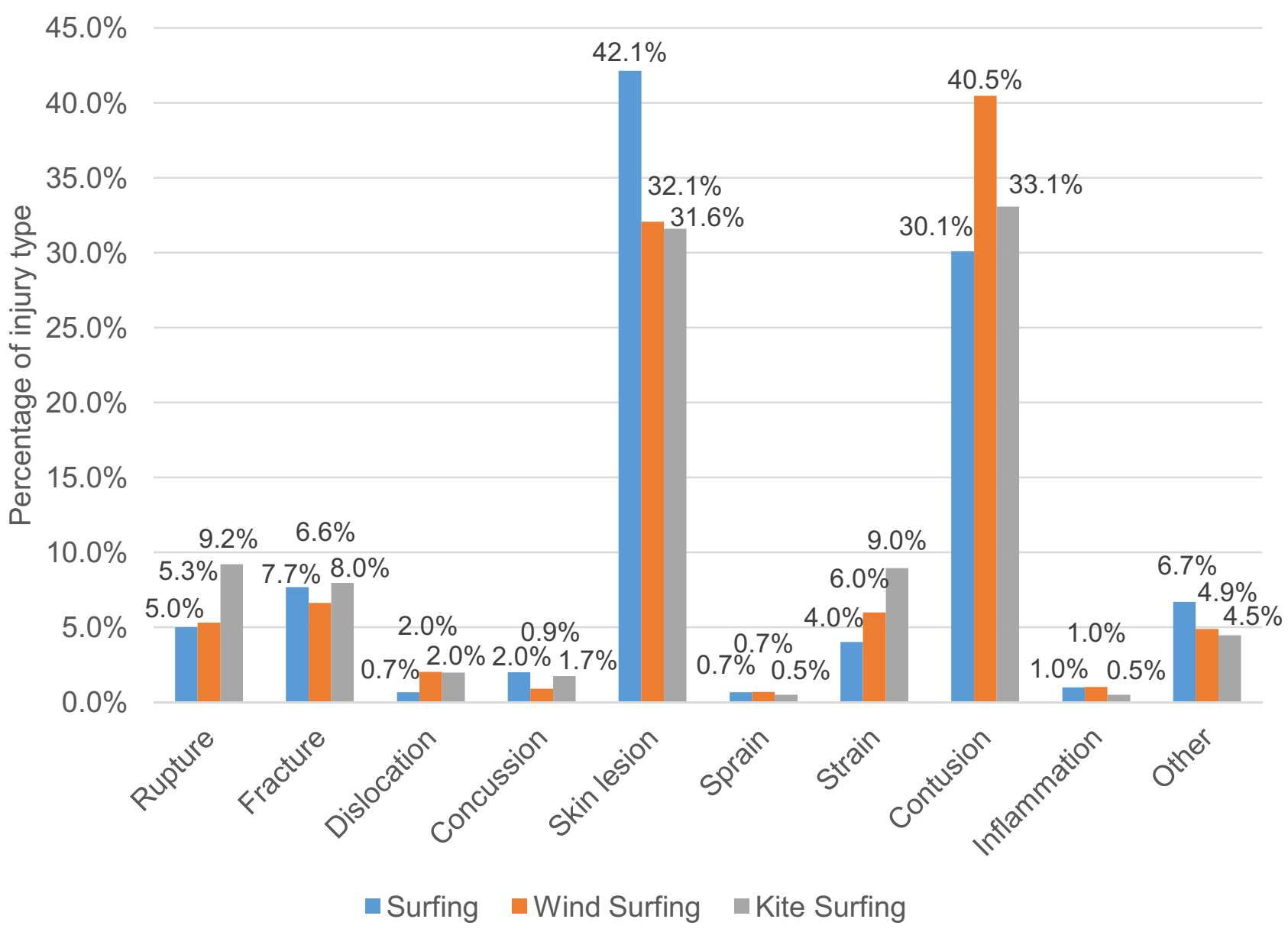

Figure 2 Distribution of injury type in surfing sports.

described in previous literature for surfing, ${ }^{3,13,17,32}$ wind surfing $^{7,22}$ and kite surfing. ${ }^{2,24}$ The main causes of injury are recklessness and overpowered material, where contact with own material results in skin lesions. Parts of the board, such as the sharp fins or the tail, are mainly responsible. ${ }^{7,29}$ Development of new fin and board designs may help prevent these injuries. In surfing, a too strong surf and therefore contact with the sea ground or collision with the board are also responsible for this type of injury. ${ }^{8,18}$ Falls caused by high waves also lead to serious injuries, such as fractures, as described in other studies in surfing. ${ }^{25,30}$ In our previous

Table 2 Most Frequent Injuries in Each Surfing Sport (with Proportion of All Injuries in the Respective Type of Sport)

\begin{tabular}{|c|c|c|c|}
\hline & Surfing & Wind Surfing & Kite Surfing \\
\hline Most frequent injury & Foot - Skin lesion $(n=38 ; 12.7 \%)$ & Foot - Skin lesion $(n=220 ; 11.7 \%)$ & Foot - Skin lesion $(n=53 ; 13.2 \%)$ \\
\hline $\begin{array}{l}\text { Second most frequent } \\
\text { injury }\end{array}$ & Head - Skin lesion $(n=24 ; 8.0 \%)$ & Thigh - Contusion $(n=\mid 42 ; 7.5 \%)$ & Thigh - Contusion $(n=26 ; 6.5 \%)$ \\
\hline Third most frequent injury & Thigh - Skin lesion $(n=22 ; 7.4 \%)$ & Trunk - Contusion $(n=140 ; 7.4 \%)$ & $\begin{array}{l}\text { Hand/Wrist }- \text { Skin lesion }(n=26 \text {; } \\
6.5 \%)\end{array}$ \\
\hline Forth most frequent injury & Head - Contusion $(n=19 ; 6.4 \%)$ & Thigh - Skin lesion $(n=124 ; 6.6 \%)$ & Trunk - Contusion $(n=25 ; 6.2 \%)$ \\
\hline Fifth most frequent injury & Trunk - Contusion $(n=16 ; 5.4 \%)$ & $\begin{array}{l}\text { Hand/Wrist - Skin lesion }(n=112 \text {; } \\
6.0 \%)\end{array}$ & Foot - Skin lesion $(n=21 ; 5.2 \%)$ \\
\hline
\end{tabular}


Table 3 Environmental Conditions and Injury Mechanism During the Injury

\begin{tabular}{|c|c|c|c|}
\hline & Surfing $(n=73)$ & Wind Surfing $(n=548)$ & Kite Surfing $(n=\mid 77)$ \\
\hline & n (\%) & n (\%) & n (\%) \\
\hline \multicolumn{4}{|c|}{ Wind Conditions (Only for WS and KS) } \\
\hline I-3 Beaufort (Bft) & & $13(2.3)$ & $4(2.3)$ \\
\hline $3-5 \mathrm{Bft}$ & & $236(43.1)$ & $108(61.0)$ \\
\hline $5-9 \mathrm{Bft}$ & & $292(53.3)$ & $63(35.6)$ \\
\hline$>9 \mathrm{Bft}$ & & $7(1.3)$ & $2(1.1)$ \\
\hline \multicolumn{4}{|c|}{ Surge and Wave Conditions (Only for S) } \\
\hline Surge and waves of up to $I \mathrm{~m}$ & II (I5.0) & & \\
\hline Surge and waves of $\mathrm{I}-3 \mathrm{~m}$ & $54(74.0)$ & & \\
\hline Surge and waves of more than $3 \mathrm{~m}$ & $8(11.0)$ & & \\
\hline \multicolumn{4}{|l|}{ Injury Cause and Mechanism } \\
\hline Own incompetence /recklessness & $16(21.9)$ & $189(34.5)$ & $65(36.7)$ \\
\hline Skidding fall & $13(17.8)$ & I58 (28.8) & $45(25.4)$ \\
\hline Overpowered material & $5(6.9)$ & $118(21.5)$ & $27(15.3)$ \\
\hline Too strong surf & $18(24.7)$ & $28(5.1)$ & $13(7.3)$ \\
\hline Material failure & $2(2.7)$ & $15(2.7)$ & $5(2.8)$ \\
\hline Collision & $9(12.3)$ & $10(1.8)$ & $2(1.1)$ \\
\hline Other external influence & $9(12.3)$ & $28(5.1)$ & 21 (11.9) \\
\hline
\end{tabular}

research, surfing in a too big surf was associated with a 2.4 times greater risk of injury. ${ }^{23}$ In particular amateur and beginners should be wary of surfing in too rough conditions to minimize the risk of injury. The risk for infection is significantly higher in wounds resulting from a contact with rocks or the sea ground and these should be carefully monitored. ${ }^{32}$ McArthur et al also described contact with the own surfboard as a major mechanism of injury in $38.6 \%$ of cases, mainly resulting in skin lesions. ${ }^{21}$ Likewise, in wind surfing the board was identified as the main source of injury. ${ }^{22}$ Overpowered material, such as a too large sail, and own negligence were the most common reasons for injury. $^{28}$ This is in line with our results where injuries occurred predominantly at wind conditions of $5 \mathrm{Bft}$ and higher, and created a significant problem in combination with overpowered material and a too large sail. Similarly, contusions occurred in all mentioned disciplines of sport with an equal mechanism. Especially in kite surfing, a higher proportion of severe injuries $(20.9 \%)$, such as fractures, dislocations, ruptures and concussions, was found. Previous studies have already shown a high percentage of fractures in kite surfing. ${ }^{15}$ Compared with team sports (at least 35.4\%), however, the rate of severe injuries in kite surfing was still lower. ${ }^{19}$ Tricks and uncontrolled jumps with subsequent falls are reported here as mechanisms of injuries. ${ }^{2,26}$ These falls are often associated with high-impact collisions with water or land where athletes are not able to detach the kite from the harness. With their sail, athletes are passively exposed to the wind and can sometimes lose control in tough breezes. ${ }^{6,24}$ However, the majority of injuries in kite surfing was registered under wind conditions of under $5 \mathrm{Bft}$. We found only a small number of injuries caused by collision with other athletes or persons on the beach or the sea. Furness et al, on the other hand, accounted for half of the injuries direct contact as major mechanism. ${ }^{13}$

As well as injury epidemiology, this study also covers statistics on training characteristics of the athletes. Benefits of sufficient strength training are well known for general population, as well as sportswomen and men. Positive effects on muscle mass, mobility, strength, speed and endurance as well as impact on metabolism and mental health are described. ${ }^{4,20,31}$ Strength training was the most popular supplement to surfing, windsurfing and kitesurfing in our study. More sport-specific differences were seen in surfing, where skate boarding and snowboarding also enjoy high popularity. Due to a similar motion sequence and biomechanics, these sports are particularly suitable for 
Table 4 Training Pattern of Surfing, Wind Surfing and Kite Surfing Athletes (Multiple Answers Were Possible for the Additional Types of Training)

\begin{tabular}{|c|c|c|c|}
\hline & Surfing $(n=61)$ & Wind Surfing $(n=45 I)$ & Kite Surfing $(n=137)$ \\
\hline & n (\%) & n (\%) & n (\%) \\
\hline \multicolumn{4}{|c|}{ Training Days Per Year in Particular Surfing Sport } \\
\hline I-7 days & $2(3.3)$ & $28(6.2)$ & $12(8.8)$ \\
\hline $7-14$ days & $5(8.2)$ & $99(21.9)$ & $18(13.1)$ \\
\hline 14-30 days & $15(24.6)$ & $192(42.6)$ & $45(32.8)$ \\
\hline$>30$ days & $39(63.9)$ & $132(29.3)$ & $62(45.3)$ \\
\hline \multicolumn{4}{|c|}{ Training Hours Per Workout } \\
\hline$<$ I hour & I (I.6) & $0(0)$ & I $(0.7)$ \\
\hline I-2 hours & $20(32.9)$ & $57(12.6)$ & $26(19.0)$ \\
\hline $2-4$ hours & $29(47.5)$ & $279(6 \mid .9)$ & $88(64.2)$ \\
\hline$>4$ hours & II (I8.0) & II $5(25.5)$ & $22(16.1)$ \\
\hline \multicolumn{4}{|c|}{ Additional Types of Training } \\
\hline Surfing & - & $71(15.7)$ & $25(18.2)$ \\
\hline Wind Surfing & $5(8.2)$ & - & $23(16.8)$ \\
\hline Kite Surfing & $3(4.9)$ & $31(6.9)$ & - \\
\hline Mountain biking & $14(23.0)$ & $138(30.6)$ & $45(32.8)$ \\
\hline Skateboarding & $26(42.6)$ & $32(7.1)$ & $19(13.9)$ \\
\hline Inline skating & $3(4.9)$ & $69(15.3)$ & $30(21.9)$ \\
\hline Climbing & $10(16.4)$ & 41 (9.1) & $18(13.1)$ \\
\hline Snowboarding & $31(50.8)$ & $146(32.4)$ & $70(5 \mathrm{I} .1)$ \\
\hline Skiing & $12(19.7)$ & $159(35.3)$ & $43(31.4)$ \\
\hline Other fun sports & $9(14.8)$ & $57(12.6)$ & $25(18.2)$ \\
\hline Ball or setback games & $17(27.9)$ & $106(23.5)$ & $32(23.4)$ \\
\hline Team sports & $20(32.9)$ & $76(16.9)$ & $27(19.7)$ \\
\hline Fighting sports & $5(8.2)$ & $24(5.3)$ & $10(7.3)$ \\
\hline Strength training /Gym & $31(50.8)$ & $178(39.5)$ & $63(46.0)$ \\
\hline Other & $15(24.6)$ & $94(20.8)$ & $28(20.4)$ \\
\hline
\end{tabular}

land training and have also been tried and practiced by over $80 \%$ of surfers. ${ }^{12}$

This study showed several limitations due to study design. The retrospective design of the study captured only interested athletes and did not cover all injuries in a specific area or time. The method of data collection may also result in the under-reporting of less severe injuries because of a focus on more severe injuries by athletes. The validity of self-reported injuries in water sports is unknown. Another drawback of the study is the incomplete coverage of the exact exposure with which a calculation of incidences would be possible. Detailed collection of exposure is especially in recreational sport hard to accomplish. However, aim of the study was to provide not information about incidences, but on epidemiology of injuries in surfing, wind surfing and kite surfing. Athletes were not clearly divided into professionals and amateurs, so further differentiation within sports was not possible. The chosen method generated the largest possible data set, which benefits from the data collection by a retrospective online survey. Thus, the most detailed and comprehensive basis possible was created for this study.

\section{Conclusion}

This unique study compared injury epidemiology and mechanism in the three most popular surfing sports, wind surfing, kite surfing and surfing. Overall injuries were located mainly in the lower extremity. While skin lesions of the foot frequently occurred in wind surfing, surfing and kite surfing, a high proportion of head injuries was registered in surfing. Overall the main injury type in this study 
were non-severe injuries such as contusions and skin lesions. This study provides an overview of the epidemiology of injuries in various water sports.

\section{Acknowledgment}

This publication was supported by the Open Access Publication Fund of the University of Wuerzburg.

\section{Disclosure}

The authors report no conflicts of interest in this work.

\section{References}

1. van Bergen CJA, Commandeur JP, Weber RIK, et al. Windsurfing vs kitesurfing: injuries at the north sea over a 2 -year period. World J Orthop. 2016;7:814-820. doi:10.5312/wjo.v7.i12.814

2. Bourgois JG, Boone J, Callewaert M, et al. Biomechanical and physiological demands of kitesurfing and epidemiology of injury among kitesurfers. Sports Med. 2014;44:55-66. doi:10.1007/ s40279-013-0103-4

3. Burgess A, Swain MS, Lystad RP. An Australian survey on health and injuries in adult competitive surfing. J Sports Med Phys Fitness. 2019;59:462-468. doi:10.23736/S0022-4707.18.08381-0

4. Cauza E, Hanusch-Enserer U, Strasser B, et al. The relative benefits of endurance and strength training on the metabolic factors and muscle function of people with type 2 diabetes mellitus. Arch Phys Med Rehabil. 2005;86:1527-1533. doi:10.1016/j.apmr.2005.01.007

5. Chater R. How much does it cost to kitesurf? IKSURFMAG; 2020. Free Kitesurfing Magazine.

6. Dunne L, Murphy E, Dawson PH, Leonard M. Kite surfing: epidemiology of trauma. BMJ Case Rep. 2018. doi:10.1136/bcr-2017223935

7. Dyson R, Buchanan M, Hale T. Incidence of sports injuries in elite competitive and recreational windsurfers. $\mathrm{Br} J$ Sports Med. 2006;40:346-350. doi:10.1136/bjsm.2005.023077

8. Falconi A, Flick D, Ferguson J, Glorioso JE. Spinal cord injuries in wave-riding sports: the influence of environmental and sport-specific factors. Curr Sports Med Rep. 2016;15:116-120. doi:10.1249/ JSR.0000000000000246

9. Farley ORL, Abbiss CR, Sheppard JM. Performance analysis of surfing: a review. J Strength Cond Res. 2017;31:260-271. doi:10.1519/JSC.0000000000001442

10. Farley ORL, Harris NK, Kilding AE. Physiological demands of competitive surfing. J Strength Cond Res. 2012;26:1887-1896. doi:10.1519/JSC.0b013e3182392c4b

11. Farley ORL, Secomb JL, Raymond ER, et al. Workloads of competitive surfing: work-to-relief ratios, surf-break demands, and updated analysis. J Strength Cond Res. 2018;32:2939-2948. doi:10.1519/ JSC.0000000000002659

12. Furley P, Dörr J, Loffing F. Goofy vs. Regular: laterality effects in surfing. Laterality. 2018;23:629-642. doi:10.1080/ 1357650X.2018.1433192

13. Furness J, Hing W, Walsh J, et al. Acute injuries in recreational and competitive surfers: incidence, severity, location, type, and mechanism. Am J Sports Med. 2015;43:1246-1254. doi:10.1177/ 0363546514567062
14. Gomez AT, Rao A. Adventure and extreme sports. Med Clin North Am. 2016;100:371-391. doi:10.1016/j.mcna.2015.09.009

15. Grunner S, Kotlarsky P, Berkovich Y, et al. Epidemiology of kite surfing injuries among recreational athletes. Isr Med Assoc J. 2016;18:272-274.

16. Jubbal KT, Chen C, Costantini T, et al. Analysis of surfing injuries presenting in the acute trauma setting. Ann Plast Surg. 2017;78: S233-S237. doi:10.1097/SAP.0000000000001026

17. Klick C, Jones CMC, Adler D. Surfing USA: an epidemiological study of surfing injuries presenting to US EDs 2002 to 2013. Am J Emerg Med. 2016;34:1491-1496. doi:10.1016/j.ajem.2016.05.008

18. Kozminski BU, Ahmed N, Cautela FS, et al. Surfing-related head injuries presenting to United States emergency departments. J Orthop. 2020;19:184-188. doi:10.1016/j.jor.2019.11.042

19. Krutsch W, Krutsch V, Hilber F, et al. 11.361 sports injuries in a 15-year survey of a Level I emergency trauma department reveal different severe injury types in the 6 most common team sports. Sportverletz Sportschaden. 2018;32:111-119. doi:10.1055/s-05833792

20. Lum D, Barbosa TM. Brief review: effects of isometric strength training on strength and dynamic performance. Int J Sports Med. 2019;40:363-375. doi:10.1055/a-0863-4539

21. McArthur K, Jorgensen D, Climstein M, Furness J. Epidemiology of acute injuries in surfing: type, location, mechanism, severity, and incidence: a systematic review. Sports (Basel). 2020. doi:10.3390/ sports 8020025

22. Mettler R, Biener K. [Athletic injuries in wind surfing]. Schweiz Z Sportmed. 1991;39:161-166. German

23. Nathanson A, Bird S, Dao L, Tam-Sing K. Competitive surfing injuries: a prospective study of surfing-related injuries among contest surfers. Am J Sports Med. 2007;35:113-117. doi:10.1177/ 0363546506293702

24. Nickel C, Zernial O, Musahl V, et al. A prospective study of kitesurfing injuries. Am J Sports Med. 2004;32:921-927. doi:10.1177/ 0363546503262162

25. Patel BJ, Heath MR, Geannette CS, et al. When the wave breaks you: magnetic resonance imaging findings after surfing injuries. Sports Health. 2020;12:88-93. doi:10.1177/1941738119880863

26. Pikora TJ, Braham R, Hill C, Mills C. Wet and wild: results from a pilot study assessing injuries among recreational water users in Western Australia. Int J Inj Contr Saf Promot. 2011;18:119-126. doi:10.1080/17457300.2010.540333

27. Pikora TJ, Braham R, Mills C. The epidemiology of injury among surfers, kite surfers and personal watercraft riders: wind and waves. Med Sport Sci. 2012;58:80-97. doi:10.1159/000338583

28. Prymka M, Plötz GM, Jerosch J. [Injury mechanisms in windsurfing regatta]. Sportverletz Sportschaden. 1999;13:107-111. German. doi:10.1055/s-2007-993325

29. Ruijs ACJ, Langenberg LC, Rezzouk J. Finger trauma due to surfing; a case series and analysis of fracture patterns. J Hand Surg Asian Pac. 2017;22:10-13. doi:10.1142/S0218810417500010

30. Sano A, Yotsumoto T. Chest injuries related to surfing. Asian Cardiovasc Thorac Ann. 2015;23:839-841. doi:10.1177/ 0218492315591103

31. Suchomel TJ, Nimphius S, Bellon CR, Stone MH. The importance of muscular strength: training considerations. Sports Med. 2018;48:765-785. doi:10.1007/s40279-018-0862-z

32. Sunshine S. Surfing injuries. Curr Sports Med Rep. 2003;2:136-141. doi:10.1249/00149619-200306000-00005 


\section{Publish your work in this journal}

Open Access Journal of Sports Medicine is an international, peerreviewed, open access journal publishing original research, reports, reviews and commentaries on all areas of sports medicine. The manuscript management system is completely online and includes a very quick and fair peer-review system. Visit http://www.dovepress. com/testimonials.php to read real quotes from published authors.

Submit your manuscript here: http://www.dovepress.com/open-access-journal-of-sports-medicine-journal 